\title{
Ventilator-induced diaphragm dysfunction: time for (contrlaction!
}

\author{
Ghislaine Gayan-Ramirez
}

Affiliation: Respiratory Muscle Research Unit, Laboratory of Pneumology and Respiratory Division, Katholieke Universiteit Leuven, Leuven, Belgium.

Correspondence: G. Gayan-Ramirez, Labo Ademspieren, Onderwijs en Navorsing 1 bus 706, Herestraat 49, B-3000 Leuven, Belgium. E-mail: ghislaine.gayan-ramirezamed.kuleuven.be

0 @ERSpublications

New studies indicate that diaphragm pacing techniques could protect against ventilator-induced diaphragm injury http://ow.ly/kTvSo

During the past 10 years, intensive experimental research has focused on the effects of mechanical ventilation on the diaphragm. Whatever the animal species studied, all these studies have consistently shown that mechanical ventilation impaired diaphragm function, resulting in the so-called ventilatorinduced diaphragm dysfunction (VIDD) [1-9]. The development of this effect is rapid and worsens with the time spent on the ventilator [5]. It is associated with early diaphragm fibre atrophy leading, ultimately, to diaphragm weight loss and to diaphragm ultrastructural alterations, with disorganisation of the sarcomere's architecture [8]. Oxidative stress, decreased protein synthesis and increased proteolysis have been all reported in the diaphragm after mechanical ventilation [8]. These data revealed that a healthy diaphragm was made diseased after mechanical ventilation.

For a long time, the importance of these data has been neglected, probably because of the experimental nature of the studies. But the study of LeviNe et al. [10] in ventilated brain-dead organ donors, which revealed rapid diaphragm fibre atrophy and enhanced proteolysis, as in animal models, highlighted the fact that the mechanical ventilation effect was not exclusive to laboratory models. Subsequent studies in animal models, and also in humans, have further documented the impact of controlled mechanical ventilation on the diaphragm [11-20].

Despite this evidence, the impact of VIDD as an important component of diaphragm disability during mechanical ventilation remains questioned. It has been claimed that the available data pertain to controlled mechanical ventilation, a ventilation mode which is not the preferential mode of ventilation in patients. Well, this is true, although this ventilation mode is a necessary tool in particular situations (e.g. in patients treated with neuromuscular blocking agents, in attempts to minimise oxygen consumption, and in patients with central neurological problems) and is therefore still being used in the intensive care unit [21]. But other ventilation modes may not be as innocent as it is believed. Experimental data showed that 3 days of assist-control mechanical ventilation in healthy animals resulted in about 15\% loss in maximal diaphragm force, which is obviously far less than the $45 \%$ reduction seen with controlled mechanical ventilation [22], but still indicative that it is also harmful. Along the same lines, pressure support ventilation that did not affect diaphragm proteolysis or synthesis, in contrast to controlled mechanical ventilation, induced as much diaphragmatic oxidative stress as controlled mechanical ventilation did [23].

Because the debate on whether VIDD is a myth or a reality is still going on, little has been done to develop strategies to minimise these effects, except for the use of pharmacological agents in experimental models of healthy animals [24-27]. But we can do more and in this issue of European Respiratory Journal, MASMOUDI et al. [28] present preliminary original and provocative results that indicates it is time for (contr)action. The

Received: May 022013 | Accepted: May 022013

Conflict of interest: None declared.

Copyright @ERS 2013 
authors examined the potential benefit of diaphragmatic pacing during mechanical ventilation in ventilated sheep. In this study, intradiaphragmatic phrenic nerve stimulation electrodes were placed bilaterally in the hemidiaphragms using a thoraco-endoscopic approach but only one diaphragm was stimulated during the experiments. Diaphragm pacing was applied within the $2 \mathrm{~h}$ after mechanical ventilation was started. The stimulation sessions consisted of 30-min stimulation every $4 \mathrm{~h}, 18$ breaths per minute at a stimulation frequency of $20 \mathrm{~Hz}$. Diaphragm fibre dimensions and proportion, and qualitative structural abnormalities were compared between mechanically ventilated hemidiaphragm (non-stimulated) and mechanically ventilated and stimulated hemidiaphragm. One animal suddenly died after $48 \mathrm{~h}$ of mechanical ventilation while the two others were sacrificed at $72 \mathrm{~h}$. There are two important observations in this study. First, reduced diaphragm type I surface developed over time in the two hemidiaphragms when comparing dimension at 48 and $72 \mathrm{~h}$ but this effect was less pronounced in the stimulated hemidiaphragm than in the non-stimulated one. But more importantly, hemidiaphragm stimulation was able to preserve type II fibre dimension compared to the non-stimulated hemidiaphragm showing reduced type II surface at $72 \mathrm{~h}$. Secondly, the histological pictures clearly show that hemidiaphragm stimulation during mechanical ventilation fully preserved the hemidiaphragm from severe damage such as hypercontracted fibres, lipid droplet accumulation, and oedema with fibre disorganisation. Of note, there were no changes in diaphragm fibre proportion in any of the conditions. This study again confirms that the time course of the events is rapid, suggesting that diaphragm pacing probably needs to be instituted as soon as possible after the start of mechanical ventilation, given the severe diaphragm damage reported at $48 \mathrm{~h}$ (and maybe even earlier). Intervention may obviously be more potent when applied early and not once extended injury has developed.

What did we learn from these preliminary data? That the diaphragm of a healthy animal becomes ill as a result of mechanical ventilation is not new. But the fact that diaphragm pacing does preserve diaphragm architecture and minimise, or even counterbalance, fibre atrophy has never been documented before. The effects are remarkable and one does not need to be an expert to understand the importance of these findings: the pictures are indicative. Of course, this is a crude and preliminary study involving a few animals and there is still a lot to do. But one should acknowledge that the study is very elegant in its approach to achieving its goal, and the results are encouraging.

What can we expect from these data? Well, intuitively, one would expect diaphragm contractility to be better preserved in the paced diaphragm as obviously a chaotic and damaged structure, as seen in the mechanically ventilated diaphragm, cannot be without consequence for diaphragm function. This is, however, not a guarantee yet and has to be investigated in future research, but still the observation is encouraging. The fact that fibre dimensions seem to be better maintained after diaphragm pacing may also contribute to preservation of diaphragm function, although we know that this is not the only mechanism involved. At least, on a long-term we may expect diaphragm mass to be spared. And if we maintain optimism, it can be speculated that all of this would make the diaphragm better prepared for resuming spontaneous breathing when mechanical ventilation is stopped. However, for the time being the study cannot be considered as any more than a proof of concept, since many issues need to be addressed before drawing firm conclusions.

What do we need to document in a first instance? It is clear that the study provides promising data on this field but, being realistic, there is still a long way before being conclusive, as clearly acknowledged by the authors. As mentioned previously, as minimum the diaphragm function issue needs to be addressed and sample population enlarged. Ideally, diaphragm strength should be preserved but diaphragm fatigue should be imperatively avoided, particularly because recovery from fatigue may be long and this would definitely compromise the purpose of this strategy. As such, the pacing protocol should be optimised in order to reach these goals. Existing experience with long-term diaphragm pacing could be helpful for this purpose, although the time frame and purpose (ventilatory support in quadriplegia versus preservation of diaphragm contractility) are different. To that extent, the long-term effect beyond $72 \mathrm{~h}$ but within the time frame for this particular situation should be investigated in light of diaphragm adaptation towards a type I fibre with long-term low-frequency stimulation: would this be beneficial in this context or not? Further, the onset and duration of diaphragm pacing need to be determined: in theory, it has been suggested that diaphragm pacing should begin on the second day of mechanical ventilation and continued during the period the patient is placed on the ventilator [29]. The data of the current preliminary study suggest that this may be too late, at least for controlled mode in healthy animals. A relevant point is also to determine the minimal level of diaphragm activity to be achieved to preserve its function. This is actually a crucial point that is also warranted for the next generation of ventilators (e.g. NAVA, PavPlus). Finally, from a research point of view, the mechanisms by which diaphragm pacing may protect the diaphragm from VIDD would also merit investigation. 
Is this strategy relevant? A priori this cannot be worse than doing nothing while maintaining mechanical ventilation but, in truth, the benefit of the strategy needs to be demonstrated. The major difficulty is to convince opinion to address this issue and if it takes as long as for VIDD, this is not for a near future. Remember that the first experimental data showing that mechanical ventilation was harmful for the diaphragm appeared in 1994 [4]; it took 14 years for the first human study to address this question [10]. However, we should have been alerted by those data especially because the over-simplified design of these models compared to the reality in the intensive care unit resulted in impressive effects on a functioning diaphragm before institution of mechanical ventilation. Assuming that the ventilation mode used in these experimental models is the sole risk factor for VIDD may be an easy conclusion. It is true that the change in mentality emphasising the importance of maintaining some diaphragm activity with ventilator support is real progress, but this may not be enough. First, this is not applicable to every situation, with controlled ventilation mode still being used in some patients. Although this represents a small minority, and despite the fact its use is as short as possible, this may be very harmful and lead to complication. It might be even worse than would be expected from data obtained in studies of healthy diaphragm, since diseased diaphragm may be more vulnerable and susceptible to the effect of mechanical ventilation, as suggested by recent experimental model [30]. Secondly, other ventilation modes, although certainly more appropriate with the concept of maintaining persistent diaphragm activity, may not necessarily be as harmless as believed [22, 23]. Experimental data indicates loss of diaphragm force after 3 days of assist-control mechanical ventilation [22] and increased protein oxidative stress after $18 \mathrm{~h}$ of pressure support mechanical ventilation [23]. The extent to which longer duration of either of these ventilation modes would be more harmful for the diaphragm is not known.

It is perhaps worthwhile to stress that the diaphragm is a skeletal muscle and, like other skeletal muscles, it is susceptible to reduced activity but it can also be trained. While the importance of maintaining persistent activity for skeletal limb muscles is now well accepted and a lot of energy has been invested in developing different techniques for rehabilitation (even for intensive care unit patients), this aspect has been neglected for the diaphragm, except for a few cases. With the exciting data of MASMOUDI et al. [28], maybe we can hope that research will be stimulated on the basis that it may be wise to consider this concept. Even if it is evident that VIDD is not the unique factor responsible for diaphragm dysfunction in ventilated patients, and although its contribution might be only a part of the iceberg, it is worth acting on it. Instead of debating the importance of VIDD, efforts and energy should be combined to investigate the potential of diaphragm pacing in VIDD, in order to develop appropriate techniques for temporary pacing in patients. Further experimental research is warranted with the support of clinicians. And, for the most pessimistic ones, they should keep in mind that, unless something has been refuted, it is still possible. Having said that, it seems reasonable to assume that it is time for (contr)action!

\section{References}

1 Anzueto A, Peters JI, Tobin MJ, et al. Effect of prolonged controlled mechanical ventilation on diaphragmatic function in healthy adult baboon. Crit Care Med 1997; 25: 1187-1190.

2 Capdevila X, Lopez S, Bernard N, et al. Effects of controlled mechanical ventilation on respiratory muscle contractile properties in rabbits. Intensive Care Med 2003; 29: 103-110.

3 Gayan-Ramirez G, de Paepe K, Cadot P, et al. Detrimental effects of short-term mechanical ventilation on diaphragm function and IGF-I mRNA in rats. Intensive Care Med 2003; 29: 825-833.

4 Le Bourdelles G, Viires N, Boczkowski J, et al. Effects of mechanical ventilation on diaphragmatic contractile properties in rats. Am J Respir Crit Care Med 1994; 149: 1539-1544.

5 Powers SK, Shaneley RA, Coombes JS, et al. Mechanical ventilation results in progressive contractile dysfunction in the diaphragm. J Appl Physiol 2002; 92: 1851-1858.

6 Radell PJ, Remahl S, Nichols DG, et al. Effects of prolonged mechanical ventilation and inactivity on piglet diaphragm function. Intensive Care Med 2002; 28: 358-364.

7 Sassoon CSH, Caiozzo VJ, Manka A, et al. Altered diaphragm contractile properties with controlled mechanical ventilation. J Appl Physiol 2002; 92: 2585-2595.

8 Vassilakopoulos T, Petrof BJ. Ventilator-induced diaphragmatic dysfunction. Am J Respir Crit Care Med 2004; 169: 336-341.

9 Yang L, Luo J, Bourdon J, et al. Controlled mechanical ventilation leads to remodelling in the rat diaphragm. Am J Respir Crit Care Med 2002; 166: 1135-1140.

10 Levine S, Nguyen T, Taylor N, et al. Rapid disuse atrophy of diaphragm fibers in mechanically ventilated humans. N Engl J Med 2008; 358: 1327-1335.

11 Davis RT III, Bruells CS, Stabley JN, et al. Mechanical ventilation reduces rat diaphragm blood flow and impairs oxygen delivery and uptake. Crit Care Med 2012; 40: 2858-2866.

12 Hermans G, Agten A, Testelmans D, et al. Increased duration of mechanical ventilation is associated with decreased diaphragmatic force: a prospective observational study. Crit Care 2010; 14: R127.

13 Hussain SN, Mofarrahi M, Sigala I, et al. Mechanical ventilation-induced diaphragm disuse in humans triggers autophagy. Am J Respir Crit Care Med 2010; 182: 1377-1386.

14 Jaber S, Petrof BJ, Jung B, et al. Rapidly progressive diaphragmatic weakness and injury during mechanical ventilation in humans. Am J Respir Crit Care Med 2011; 183: 364-371. 
15 Levine S, Biswas C, Dierov J, et al. Increased proteolysis, myosin depletion, and atrophic AKT-FOXO signaling in human diaphragm disuse. Am J Respir Crit Care Med 2011; 183: 483-490.

16 Mrozek S, Jung B, Petrof BJ, et al. Rapid onset of specific diaphragm weakness in a healthy murine model of ventilator-induced diaphragmatic dysfunction. Anesthesiology 2012; 117: 560-567.

17 Picard M, Jung B, Liang F, et al. Mitochondrial dysfunction and lipid accumulation in the human diaphragm during mechanical ventilation. Am J Respir Crit Care Med 2012; 186: 1140-1149.

18 Schellekens WJ, van Hees HW, Vaneker M, et al. Toll-like receptor 4 signaling in ventilator-induced diaphragm atrophy. Anesthesiology 2012; 117: 329-338.

19 Smuder AJ, Hudson MB, Nelson WB, et al. Nuclear factor-kappaB signaling contributes to mechanical ventilationinduced diaphragm weakness. Crit Care Med 2012; 40: 927-934.

20 van Hees HW, Schellekens WJ, Andrade Acuna GL, et al. Titin and diaphragm dysfunction in mechanically ventilated rats. Intensive Care Med 2012; 38: 702-709.

21 Esteban A, Anzueto A, Alia I, et al. How is mechanical ventilation employed in the intensive care unit? An international utilization review. Am J Respir Crit Care Med 2000; 161: 1450-1458.

22 Sassoon CS, Zhu E, Caiozzo VJ. Assist-control mechanical ventilation attenuates ventilator-induced diaphragmatic dysfunction. Am J Respir Crit Care Med 2004; 170: 626-632.

23 Futier E, Constantin JM, Combaret L, et al. Pressure support ventilation attenuates ventilator-induced protein modifications in the diaphragm. Crit Care 2008; 12: R116.

24 Agten A, Maes K, Smuder A, et al. N-Acetylcysteine protects the rat diaphragm from the decreased contractility associated with controlled mechanical ventilation. Crit Care Med 2011; 39: 777-782.

25 Agten A, Maes K, Thomas D, et al. Bortezomib partially protects the rat diaphragm from ventilator-induced diaphragm dysfunction. Crit Care Med 2012; 40: 2449-2455.

26 Betters JL, Criswell DS, Shanely RA, et al. Trolox attenuates mechanical ventilation-induced diaphragmatic dysfunction and proteolysis. Am J Respir Crit Care Med 2004; 170: 1179-1184.

27 Maes K, Testelmans D, Powers S, et al. Leupeptin inhibits ventilator-induced diaphragm dysfunction in rats. Am J Respir Crit Care Med 2007; 175: 1134-1138.

28 Masmoudi H, Coirault C, Demoule A, et al. Can phrenic stimulation protect the diaphragm from mechanical ventilation-induced damage? Eur Respir J 2013; 42: 280-283.

29 Pavlovic D, Wendt M. Diaphragm pacing during prolonged mechanical ventilation of the lungs could prevent from respiratory muscle fatigue. Med Hypotheses 2003; 60: 398-403.

30 Demoule A, Le dinh M, Carreira S, et al. Impact of prolonged mechanical ventilation on sepsis-induced diaphragm dysfunction. Am J Respir Crit Care Med 2012; 185: A2702. 